\title{
Comparative assessment of quality of life of patients with schizophrenia attending a community psychiatric centre and a psychiatric hospital \\ Victoria I. Elegbede, ${ }^{1}$ Adetunji Obadeji, ${ }^{2}$ Timothy O. Adebowale ${ }^{3}$ and Lateef O. Oluwole ${ }^{2}$
}

Ghana Med J 2019; 53(2): 92-99 doi: http://dx.doi.org/10.4314/gmj.v53i2.3

\author{
${ }^{1}$ Mental Health Unit, Ace Medicare, Ota, Ogun State. \\ ${ }^{2}$ Department of Psychiatry, Ekiti State University Teaching Hospital, Ado-Ekiti, Ekiti State, Nigeria \\ ${ }^{3}$ Department of Clinical services, Neuropsychiatric Hospital, Aro, Abeokuta, Ogun State, Nigeria
}

Corresponding author: Dr A. Obadeji

E-mail: doctunjioba@yahoo.com

Conflict of interest: None declared

\begin{abstract}
SUMMARY
Background: Over the past few decades, there has been an emphasis on the de-institutionalisation of psychiatric care with a focus on community care. With Quality of Life $(\mathrm{QoL})$ as an outcome measure, this study compared the QoL of patients with schizophrenia attending a psychiatric hospital and a community psychiatric centre.

Design: This was a cross-sectional study in two psychiatric facilities

Methods: Data were obtained through a socio-demographic and clinical questionnaire; the QoL was assessed with the WHOQOL-BREF and patient satisfaction with care with CPOSS. Total and domain scores of WHOQOL-BREF for each group were calculated and compared with each other and other group characteristics. Diagnosis of schizophrenia was based on ICD-10.

Results: Participants from the two centres did not differ significantly on any of the socio-demographic characteristics measured. Similarly, there was no significant difference in their overall mean WHOQOL-BREF scores as well as the mean WHOQOL-BREF of domain scores. However, the married and females from both centres significantly had higher mean WHOQOL-BREF scores than their male counterparts. Patients in remission for more than two years or those on a single type of medication (either oral or depot preparation) from both centres significantly had higher mean WHOQOL-BREF score compared with those who had less than two years of remission or on both oral and depot preparations.

Conclusion: Overall QoL of patients managed at the two centres was comparable, with similar socio-demographic as well as clinical variables influencing QoL. This suggests that patients with schizophrenia can be well managed at community psychiatric centres.
\end{abstract}

Keywords: schizophrenia, quality of life, community psychiatric care, psychiatric hospital, patient satisfaction, treatment outcomes

Funding: None declared

\section{INTRODUCTION}

Schizophrenia, like other chronic illness, significantly impacts the Quality of Life (QoL) of the affected individuals. As we know, schizophrenia is a complex disorder that impacts on a wide range of mental functioning. The disease, along with the impact of its treatment; that is, the various side-effects of antipsychotic medications affect the overall QoL of people with this disorder. ${ }^{1}$ Like other chronic illnesses, the goal of management is to improve the quality of life. The study of QoL provides an opportunity to appraise treatment outcome based on patients' perspectives.

In the clinical setting, however, the QoL incorporates the inclusion of patients' feelings, attitudes, and opinions in medical decision making thus providing the basis for an individual's health care needs, setting therapeutic goals, and providing patient-centered holistic care. ${ }^{2-4}$ The QoL as we know is multidimensional, with different components such as person's satisfaction with his/her life as a whole, general wellbeing; the observable social and material wellbeing, satisfaction with his/her social and material well-being, as well as health and functional status. ${ }^{5}$ The World Health Organization on the other hand defined QoL as "an individual's perception of their position in life in the context of the culture and value systems in which they live and in relation to their goals, expectations, standards and concerns". 6 These definitions emphasise the multidimensional approach to QoL; the objective and the subjective nature of this construct. 
Although QoL is recognised as an important outcome measure of treatment of schizophrenia, the determinants of QoL for individuals with this disorder are not well understood. However, research has consistently reported an association with socio-demographic and clinical variables alongside symptoms of schizophrenia as major factors influencing the QoL. 5,7,8 The QoL in patients with schizophrenia has been reported to be significantly lower in males, unemployment, younger age, perceived poor social support and satisfaction with out-patient care, marital status, living conditions and financial situation, and attitude of the families towards patients' treatment. ${ }^{7,8,9}$

Similarly, clinical variables such as duration of illness, medication dosage and adherence, the presence of negative symptoms, $, 10,11$ depressive symptoms, ${ }^{7,89}$ comorbid medical problems, ${ }^{7}$ and most cognitive factors correlated significantly with QoL and to a lesser extent, positive symptoms. ${ }^{8}$ According to Novick et al., negative symptoms seem to have a larger influence on self-perceived QoL than positive symptoms, and improvement in negative symptoms is highly associated with improvements in QoL. ${ }^{12}$ Negative symptoms were found to have a high correlation with QoL in most studies. ${ }^{11,13,14}$ Likewise, depression has been reported as one of the most important factors in predicting a poor subjective QoL, ${ }^{7}, 8$, 11,15,16, nevertheless, a study had reported no significant difference in the relationship between QoL and individuals with schizophrenia with or without depression. ${ }^{17}$

The advent of antipsychotics in the fifties has led to deinstitutionalisation of psychiatric care with an emphasis on community care in most western nations. Nevertheless, the care of patients with mental illness still takes place mostly in major psychiatric hospitals in most developing countries. The QoL of patients is described as an indicator of treatment outcomes. ${ }^{5,8}$ In research and clinical practice, the assessment of the QoL is an important outcome measure in individuals with schizophrenia; both in the evaluation of improvement in QoL as well the level of functioning. In this study, we hypothesised that QoL of a patient with a diagnosis of schizophrenia managed at a typical psychiatric hospital would be significantly better than those treated at the community centres, considering the enormity of resources and various levels of mental health professionals at a typical psychiatric hospital. In line with this, we aimed at comparing the QoL of patients living with schizophrenia managed at the major psychiatric hospital and that of community mental centre; both located in Abeokuta, Nigeria and identify factors that influence such difference.

\section{METHODS}

\section{Research design}

The study is a cross-sectional comparative study of the QoL of patients with a diagnosis of schizophrenia attending the out-patient clinic of the the Neuro-Psychiatric Hospital (NPH), Aro, and the Ogun State Community Psychiatric Service Centre (OSCPSC), Oke Ilewo, both in Abeokuta, Ogun State, Nigeria.

\section{Settings}

The Neuropsychiatric Hospital is a federal government specialist hospital that offers both inpatient and out-patient psychiatric services to majorly people in the Southwestern part of Nigeria, and to some extent, those from other parts of the country. Alongside, the institution offers twenty-four-hour emergency psychiatric care, and out-patient care in the hospital runs 4 days a week by Consultant Psychiatrists, supported by trainee Psychiatrists, Psychiatric Nurses, Pharmacists as well as other mental health workers. Largely, services provided at the clinic (consultation, investigations, medications, etc.) are on a fee-for-service basis. At the time of this study, there were nine Consultant Psychiatrists, twenty-three resident doctors, ten Clinical psychologists, nine Social-workers, and four Occupational therapists, at the NPH, all collaborating for effective patient care. The centre offers both inpatient and out-patient services.

The OSCPSC, on the other hand, was established by the Ogun state government of Nigeria. The Centre was set up to promote mental health, prevent mental illnesses, and manage mental illnesses. At the time of the study, the Centre had four Psychiatric nurses, a pharmacy technician, a Medical record officer that are involved in the day to running of the Centre. Two Consultant Psychiatrists oversaw this Centre along with other community outposts in the State. Unlike the NPH, the Centre does not have the full complement of mental health workers such as Psychologists, Social-worker and Occupational therapist which are available at the NPH.

\section{Study Population}

Participants for this study were recruited from the outpatient clinics of the NPH and the OSCPSC. All consecutive out-patients aged 18 years and above, with a diagnosis of schizophrenia based on assessment by a Consultant Psychiatrist and met ICD-10 criteria for schizophrenia based on the Diagnostic Criteria for Research for ICD-10, and had attended the clinic for at least 6 months prior to the study and had at least one scheduled appointment during the study period were recruited for the study. 
Patients with comorbid medical conditions or other comorbid psychiatric diagnoses such substance use disorders, learning disability or gross psychotic, or with a neurological disorder that could interfere with the assessment were excluded from the study.

The sample size was calculated using the statistical formula for studying proportions with a population $<10,000 .{ }^{18}$ The minimum number ' $n$ ' of patients required for the study was estimated using the formula $n=z^{2} p(1-$ p) $\div d^{2}$ where: ' $z$ ' is the critical value and in a two-tailed test it is equal to 1.96 , ' $p$ ' is the estimated prevalence of out-patients with schizophrenia who had poor overall QoL, which was taken as 81 percent based on previous study, ' $\mathrm{d}$ ' is the absolute sampling error that can be tolerated. In this study, it was fixed at 5 per cent. Therefore, the minimum sample size: ' $\mathrm{n}$ ' $=1.962 \times 0.81 \times(1-0.81) \div$ $0.052=236.49=237$ (approximately). An additional 10 per cent was added to account for attrition or nonresponse. Based on this, a sample size of 260 was estimated, and this was shared equally between the two centres; that is, 130 participants from each Centre.

\section{Data Instrument}

A questionnaire was developed to assess the socio-demographic and clinical variables. Participants' QoL was measured using the short version of the World Health Organization Quality of Life (WHOQOL)-BREF, a 26-item questionnaire that assesses subjective QoL in the previous two weeks. The WHOQOL-BREF has four domains (physical health, psychological health, social relationships and environment) and two questions that measure the overall QOL and general health.

In this study, the short version of the WHO's QOL scale (WHOQOL-BREF) was used to assess the QoL of patients who met criteria for schizophrenia based on ICD10. This instrument (WHOQOL-BREF) was derived from the WHOQOL-100. The WHOQOL-BREF questionnaire contains two items on Overall QoL and General Health and 24 items of satisfaction that divided into four domains: Physical health with seven items (DOM1), psychological health with six items (DOM2), social relationships with three items (DOM3) and environmental health with eight items (DOM4). Each item of the WHOQOL-BREF is scored from 1 to 5 on a response scale. Raw domain scores for the WHOQOL were transformed to a 4-20 score according to guidelines. ${ }^{19}$ Domain scores are scaled in a positive direction (that is, higher scores denote higher QoL).

The mean score of items within each domain is used to calculate the domain score. After computing the scores, they transformed linearly to a $0-100$-scale. ${ }^{20}$
The WHOQOL-BREF is a comprehensive and culturally sensitive instrument with good psychometric properties, having a small overlap in content between symptoms and the QoL facets. ${ }^{20}$ Participants in this study were interviewed with either the English version of the WHOQOLBREF or with its validated Yoruba version (the predominant Nigerian language spoken by patients within the study setting). ${ }^{21}$ The WHOQOL-BREF has shown to have good reliability and validity for the assessment of QoL in patients living with schizophrenia with an excellent internal consistency for the total WHOQOL-BREF ( 0.88 at baseline and 0.89 at follow-up) ${ }^{22}$

Assessment of Patients' perception of satisfaction with the out-patient clinic was assessed using the Charleston Psychiatric Outpatient Satisfaction Scale (CPOSS), a 15item questionnaire scored on a 5-point Likert scale. ${ }^{23}$ It has been reported in Nigeria to be reliable and valid with high internal consistency $(0.91)$ and convergent validity ranging between $0.30-0.68 .^{24}$

\section{Ethical Consideration}

Research and Ethics Committee of the Neuropsychiatric Hospital, Aro, Abeokuta approved the research protocol. Similarly, an approval to carry out the study at the OSCPSC was also obtained from the Permanent Secretary of the Ogun State Hospitals Management Board. Written informed consent was sought and obtained from every participant after explaining the purpose of the study to each patient. Privacy and confidentiality were ensured throughout the interview.

\section{Data Analysis}

The data were analysed using Statistical Package for Social Science version 19 (SPSS Inc.). Frequency distribution and mean scores with standard deviations (SD), were computed for socio-demographic variables and clinical variables as deemed appropriate. The mean WHOQOL-BREF item scores, as well as socio-demographic and clinical variables of the respondents from the two centres, were compared using a t-test for quantitative and chi-square for qualitative variables. Analysis of Variance (ANOVA) was used to explore the relationship between the mean total WHO QOL BREF scores of participants from the two centres (NPH and OSCPSC) with socio-demographic and clinical variables. Correlation between the total CPOSS scores and the mean total WHOQOL-BREF scores were also explored. The level of significance was set at $\mathrm{p}<0.05$.

\section{RESULTS}

\section{General measures}

A total of two hundred and sixty (260) respondents who fulfilled the research criteria were approached at both centres. 
A total of 238 responded and completed the interview translating to $91.5 \%$ response rate. The 238 respondents who completed the interview were made up of 121 from $\mathrm{NPH}$ and 117 from (OSCPSC). The overall mean age for all respondents was $37.78(11.50)$ years.

\section{Socio-demographic Characteristics}

The majority of the participants at both centres were between 25 to 34 years; $42.1 \%$ for those at NPH and $51.3 \%$ for those at OSCPSC. The mean age was 37.94 (10.20) years and 37.62 (12.70) years for respondents at NPH and OSCPSC, respectively. There was no statistically significant difference in the mean age of respondents at both centres $(\mathrm{t}=0.20, \mathrm{p}=0.84)$. Except for employment status $(\mathrm{p}=0.013)$, the two groups did not differ significantly in term of other socio-demographic variables such as marital status, educational status, and religion ( $\mathrm{p}>0.05)$.

The relationship between clinical variables of participants from NPH and OSCPSC

The mean age of onset of the illness among NPH respondents was $27.0(0.14)$ years while for those at OSCPSC it was 26.0 years $(0.86)(\mathrm{t}=0.220, \mathrm{p}=0.826)$. Similarly, there was no significant difference in the mean duration of illness of the respondents from the two centers, duration of remission (the absence of active symptoms that significantly impaired the respondent's functioning), the types of antipsychotic medication, antipsychotic drug preparation and the presence of antipsychotic medication side effects ( $p>0.05)$. However, significant difference was observed in mean number of antipsychotic drugs prescribed $(\mathrm{t}=3.776, \mathrm{p}<0.001)$ and number of episodes $(\mathrm{t}=9.31, \mathrm{p}=0.022)$.

Comparison of the mean WHO QOL-BREF domains scores of the NPH and OSCPSC respondents

Table 1 shows the comparison of the mean WHO QOLBREF domains scores of NPH and OSCPSC respondents. The mean overall QoL of the NPH respondents was $4.40(\mathrm{SD}=0.89)$, while at OSCPSC, the overall $\mathrm{QoL}$ of the respondents was $4.38(0.87)$; however, the difference was not statistically significant $(\mathrm{p}=0.916)$.

Table 1 Comparison of the mean WHO QOL-BREF domains scores of the NPH and OSCPSC respondents.

\begin{tabular}{|c|c|c|c|}
\hline \multirow[t]{2}{*}{ Domains } & \multicolumn{2}{|c|}{$\begin{array}{l}\text { Mean WHO QOL-BREF score } \\
\text { (SD) }\end{array}$} & \multirow[t]{2}{*}{ p-value } \\
\hline & NPH & OSCPSC & \\
\hline Overall QOL & $4.40(0.89)$ & $4.38(0.87)$ & 0.916 \\
\hline Overall health & $4.34(1.04)$ & $4.30(1.07)$ & 0.771 \\
\hline Physical & $14.22(2.47)$ & $14.22(2.19)$ & 0.978 \\
\hline Psychological & $15.05(2.14)$ & $14.90(2.38)$ & 0.600 \\
\hline Social & $16.64(3.50)$ & $15.81(4.29)$ & 0.110 \\
\hline Environment & $15.78(2.82)$ & $15.59(2.98)$ & 0.619 \\
\hline
\end{tabular}

Similarly, there was no significant difference in the mean score at both centres on the overall health, the physical domain $(p=0.978)$, psychological domain $(p=0.600)$, social domain $(\mathrm{p}=0.110)$ and the environment domain $(\mathrm{p}=0.619)$.

\section{Comparison of the NPH and OSCPSC respondents' satisfaction with WHO QOL-BREF items}

Table 2 shows the comparison of NPH and OSCPSC respondents' WHOQOL-BREF items scores. Satisfaction with finances at both centres had the least score, with a mean score of 2.97(1.04) at NPH, and 3.02(1.04) at OSCPSC. Satisfaction with the ability to perform daily activities had the highest mean score for both participants, with a mean score of $4.43(0.89)$ and 4.44 (1.05) at NPH and OSCPSC, respectively. With the exception of the feeling of despair, there was no statistically significant difference between the mean score of each WHOQOL-BREF items of participants from the two centres.

Comparison of the mean total WHO QOL BREF scores (NPH and OSCPSC) and socio-demographic variables.

Table 3 reflects the relationship between mean total WHO QOL BREF score and socio-demographic variables of participants from the two centres. The total WHOQOL-BREF scores of the respondents at the two centres differ significantly with respect to gender $(p=0.003)$, marital status $(p=0.005)$ and level of education $(\mathrm{p}=0.043)$.

Table 2 Comparison of the NPH and OSCPSC respondents' satisfaction with WHO QOL-BREF Items

\begin{tabular}{|c|c|c|c|}
\hline \multirow[t]{2}{*}{ WHO-QOL-BREF Items } & \multicolumn{2}{|c|}{$\begin{array}{l}\text { WHO QOL-BREF Items } \\
\text { Mean Scores (SD) }\end{array}$} & \multirow[t]{2}{*}{ p-value } \\
\hline & $\mathrm{NPH}$ & OSCPSC & \\
\hline Overall QOL & $4.40(0.89)$ & $4.38(0.87)$ & 0.916 \\
\hline Overall health & $4.34(1.04)$ & $4.30(1.07)$ & 0.771 \\
\hline Physical pains & $4.26(0.95)$ & $4.18(1.23)$ & 0.592 \\
\hline Need for medical treatment & $4.27(0.98)$ & $4.35(0.82)$ & 0.510 \\
\hline Enjoyment of life & $3.98(1.0)$ & $3.95(1.15)$ & 0.852 \\
\hline Meaningfulness of life & $4.10(1.03)$ & $4.09(1.12)$ & 0.971 \\
\hline Concentration & $4.12(0.99)$ & $4.07(1.05)$ & 0.720 \\
\hline Safety & $4.06(1.13)$ & $4.12(1.15)$ & 0.675 \\
\hline Environment & $4.12(1.10)$ & $4.13(1.10)$ & 0.930 \\
\hline Energy & $4.11(1.07)$ & $3.93(1.10)$ & 0.212 \\
\hline Bodily appearance & $4.36(0.98)$ & $4.18(1.14)$ & 0.183 \\
\hline Finances & $2.97(1.04)$ & $3.02(1.04)$ & 0.711 \\
\hline Information & $3.81(1.27)$ & $3.50(1.49)$ & 0.069 \\
\hline Leisure & $3.70(1.30)$ & $3.60(1.30)$ & 0.537 \\
\hline Mobility & $4.39(0.92)$ & $4.38(0.91)$ & 0.974 \\
\hline Sleep & $4.32(1.03)$ & $4.31(1.18)$ & 0.919 \\
\hline Daily activities & $4.43(0.89)$ & $4.44(1.05)$ & 0.961 \\
\hline Capacity for work & $4.24(1.04)$ & $4.30(1.15)$ & 0.677 \\
\hline Self & $4.24(1.07)$ & $4.02(1.35)$ & 0.160 \\
\hline
\end{tabular}

Post Hoc analysis (not in the table) shows that female at the OSCPSC had a significantly higher score than the males $(\mathrm{p}=0.030$ ), and females at NPH had a significantly higher score than the males at OSCPSC $(\mathrm{p}=0.010)$. 
Similarly, married respondents significantly scored higher than those who were not married $(p=0.006)$. Furthermore, females at NPH had a significantly higher score than the males at OSCPSC $(\mathrm{p}=0.010)$. Also, NPH respondents with level of education lower than secondary school had a significantly higher score than their counterparts from OSCPSC $(\mathrm{p}=0.044)$. There were no statistically significant relationships between total mean WHO QOL BREF scores of participants from both centres with age, employment status, the location of abode and religion.

Comparison of the mean total WHO QOL BREF scores (NPH and OSCPSC) and clinical variables

Table 4 depicts the comparison of the relationship between total WHO QOL BREF score and clinical variables of participants at NPH and OSCPSC. There was a significant difference between the respondents' mean total WHOQOL-BREF scores and duration of remission $(\mathrm{p}=0.026)$, number of antipsychotic drugs prescribed $(p=0.026)$ and mode of administration of medications $(\mathrm{p}=0.032)$.

Table 3 Comparison of the mean total WHO QOL BREF scores (NPH and OSCPSC) and socio-demographic variables

\begin{tabular}{|c|c|c|c|c|}
\hline \multirow[t]{2}{*}{ Variables } & \multicolumn{2}{|c|}{$\begin{array}{l}\text { mean total WHO QOL BREF } \\
\text { Score (SD) }\end{array}$} & \multicolumn{2}{|c|}{ ANOVA } \\
\hline & NPH & OSCPC & $\mathrm{F}$ & P-value \\
\hline $\begin{array}{l}\text { Age (years) } \\
18-30 \\
>30\end{array}$ & $\begin{array}{l}108.63(12.91) \\
106.70(14.01)\end{array}$ & $\begin{array}{l}105.51(15.31) \\
105.32(15.28)\end{array}$ & 0.564 & 0.640 \\
\hline $\begin{array}{l}\text { Gender } \\
\text { Female } \\
\text { Male }\end{array}$ & $\begin{array}{l}109.33(14.09) \\
104.50(12.72)\end{array}$ & $\begin{array}{l}108.26(14.20) \\
100.78(15.83)\end{array}$ & 4.719 & 0.003 \\
\hline $\begin{array}{l}\text { Marital status } \\
\text { Married } \\
\text { Not married }\end{array}$ & $\begin{array}{l}109.09(13.44) \\
106.13(13.79)\end{array}$ & $\begin{array}{l}111.62(13.71 \\
102.27(15.07)\end{array}$ & 4.448 & 0.005 \\
\hline $\begin{array}{l}\text { Level of education } \\
<\text { secondary } \\
\text { Secondary and above }\end{array}$ & $\begin{array}{l}111.41(14.51) \\
104.43(12.40)\end{array}$ & $\begin{array}{l}103.88(16.67) \\
107.21(13.21)\end{array}$ & 2.764 & 0.043 \\
\hline $\begin{array}{l}\text { Employment status } \\
\text { Employed } \\
\text { Unemployed }\end{array}$ & $\begin{array}{l}107.74(13.47) \\
105.80(14.42\end{array}$ & $\begin{array}{l}107.13(13.55) \\
102.79(17.26)\end{array}$ & 1.418 & 0.238 \\
\hline $\begin{array}{l}\text { Location of abode } \\
\text { Abeokuta } \\
\text { Outside Abeokuta }\end{array}$ & $\begin{array}{l}105.29(14.67) \\
107.85(13.39)\end{array}$ & $\begin{array}{l}105.67(14.92) \\
104.82(16.01)\end{array}$ & 0.573 & 0.633 \\
\hline $\begin{array}{l}\text { Religion } \\
\text { Christianity } \\
\text { Other religion }\end{array}$ & $\begin{array}{l}107.12(13.40) \\
107.53(14.39)\end{array}$ & $\begin{array}{l}105.47(14.52) \\
105.19(16.92)\end{array}$ & 0.339 & 0.797 \\
\hline
\end{tabular}

Likewise, NPH respondents who were in remission for two or more years had a higher score than OSCPSC respondents who were in remission for less than two years $(p=0.031)$. Other clinical variables were not significantly associated with the mean total WHO QOL BREF score $(p<0.05)$.
Correlations between total CPOSS scores and mean total WHO BREF score

The mean (SD) CPOSS scores at NPH and OSCPC was $63.22(9.93)$ and $64.48(8.16)$ respectively. There was a positive correlation between the respondents' mean total WHOQOL-BREF score and their mean CPOSS score (Pearson's correlation $=+0.468$ and 0.479 at NPH and OSCPC respectively) $(\mathrm{p}<0.001)$.

Table 4 Comparison of the mean total WHO QOL BREF scores (NPH and OSCPSC) and clinical variables

\begin{tabular}{|c|c|c|c|c|}
\hline \multirow[t]{2}{*}{ Clinical variables } & \multicolumn{2}{|c|}{ Mean total WHO QOL BREF Score } & \multicolumn{2}{|c|}{ ANOVA } \\
\hline & NPH (SD) & OSCPSC (SD) & $\mathbf{F}$ & p-value \\
\hline $\begin{array}{l}\text { Age of onset (years) } \\
\quad<35 \\
\quad \geq 35\end{array}$ & $\begin{array}{l}107.60(13.28) \\
105.18(16.17)\end{array}$ & $\begin{array}{l}104.42(14.90) \\
110.37(16.32)\end{array}$ & 1.285 & 0.280 \\
\hline $\begin{array}{l}\begin{array}{l}\text { Duration of illness } \\
\text { (years) } \\
<5 \\
>5\end{array} \\
\end{array}$ & $\begin{array}{l}106.50(13.57) \\
107.63(13.79)\end{array}$ & $\begin{array}{l}105.61(16.74) \\
105.28(14.61)\end{array}$ & 0.388 & 0.762 \\
\hline $\begin{array}{l}\text { Duration of remission } \\
\text { (years) } \\
\quad<2 \\
\quad \geq 2\end{array}$ & $\begin{array}{l}104.40(15.19) \\
110.57(10.90)\end{array}$ & $\begin{array}{l}103.31(16.38) \\
107.42(13.84)\end{array}$ & 3.134 & 0.026 \\
\hline $\begin{array}{l}\text { No. antipsychotic } \\
\text { drugs } \\
\quad 1 \\
2 \text { or more }\end{array}$ & $\begin{array}{l}110.56(12.16) \\
106.07(14.05)\end{array}$ & $\begin{array}{l}109.20(13.55) \\
102.63(15.86)\end{array}$ & 3.134 & 0.026 \\
\hline $\begin{array}{l}\text { Type of } \\
\text { antipsychotic drugs } \\
\text { Typical } \\
\text { Atypical with or } \\
\text { without typical }\end{array}$ & $\begin{array}{l}107.40(13.79) \\
101.67(6.66)\end{array}$ & $\begin{array}{l}104.97(15.27) \\
1.423\end{array}$ & 1.423 & 0.237 \\
\hline $\begin{array}{l}\text { Preparation of } \\
\text { antipsychotic drugs } \\
\text { Oral or depot } \\
\text { Oral and depot }\end{array}$ & $\begin{array}{l}109.49(12.39) \\
106.20(14.19)\end{array}$ & $\begin{array}{l}109.22(13.55) \\
102.42(15.88)\end{array}$ & 2.977 & 0.032 \\
\hline $\begin{array}{l}\text { Any side effect } \\
\text { Yes } \\
\text { No }\end{array}$ & $\begin{array}{l}104.18(14.02 \\
108.72(13.35)\end{array}$ & $\begin{array}{l}103.63(14.72) \\
106.52(15.54)\end{array}$ & 1.584 & 0.194 \\
\hline $\begin{array}{l}\text { Appointments kept } \\
<4 \\
4\end{array}$ & $\begin{array}{l}108.85(13.98) \\
106.44(13.53\end{array}$ & $\begin{array}{l}102.90(15.93) \\
107.75(14.26)\end{array}$ & 1.698 & 0.168 \\
\hline
\end{tabular}

\section{DISCUSSION}

One of the main goals of treatment of patients with psychiatric disorders such as schizophrenia is to improve their QoL. In this study, we compared the QoL of patients with the diagnosis of schizophrenia attending a typical long-stay psychiatric hospital with those attending a community care centre. It was interesting to find out that the overall QoL of patients from the two centres were comparable; likewise, their overall health, thus disproving our hypothesis. Although patients from NPH had a higher mean overall QoL score than those from OSCPS, the difference, however, was not significant. With the exception of unpleasant feeling such as despair, the two groups of patients did not differ significantly on other WHOQOL-BREF items. 
This possibly points to the fact that the quality of care at the two centres may not differ significantly or rather; the quality of care is not the only determinant of the QoL. According to Adelufosi et al., socio-demographic and clinical factors only explained a modest part of the variance in the QoL scores, with the possibility of unmeasured 'internalised' factors contributing in a much larger sense to the variation in subjective QoL.'

Nevertheless, studies looking at re-hospitalisation of patient a year after they received hospital-based community psychiatric care, has reported a significant reduction in the rate of psychiatric admissions with improved QoL for patients managed at the community psychiatric centre as well as a decrease in the frequency of the negative symptoms. ${ }^{25,26}$ These observations have been attributed to an increase in social support which serves as a factor that modifies the effects of stressful life events..$^{25,26}$ On the other hand, studies have reported an association between long-term and intensive care use (a typical feature of a typical long-stay psychiatric hospital like the NPH) and the perceived patients' difficulty, ${ }^{27,28}$ which have influence the observation noticed in this study.

With the exception of gender, marital status and level of education the two groups did not differ significantly on comparison of socio-demographic variables and QoL. Females and the married from both centres were more likely to experience better QoL when compared with the males and the unmarried. Although the two groups did not differ significantly in term of their educational level, the level of education was observed to differentiate the two groups in term of their QoL, with those with lower education from the NPH more likely to have better QoL compared with those with higher education, however, the reverse was the case with participants from OSCPSC where those with higher education had higher mean WHOQOL-BREF scores. The reason for this may be a subject of further research.

Nonetheless, studies looking at the relationship between socio-demographic variables have reported negative association between QoL and the male gender, single marital status, low income, unemployment, higher educational attainment, worse living condition, worse financial situation, financial dependent ${ }^{7-9,29}$ while being in a paid job, living with spouses or other family members, supportive social relations have been shown to be positively related to QoL scores. ${ }^{30,31}$ Even though male gender had been associated with poorer QoL by most researchers, a few others have reported better QoL in male patients with schizophrenia ${ }^{32}$ or insignificant association. ${ }^{33}$
Of the clinical variables measured, three variables (the mean number of antipsychotics, the mean clinic attendance and numbers of episodes) differentiate the two groups. Those from NPH were more likely to have had a higher number of antipsychotics, had more patients with more than two episodes and to have kept higher numbers of appointment in the last four appointments given. The fact that the Centre is a referral centre with relatively more chronically ill patients or possibly with the worse condition may account for this difference. However, the relationship between clinical variables and the mean total WHO QoL BREF scores showed that those in remission for more than two years and those on one form of antipsychotic (oral or depot) from both centres significantly had a better quality of life.

Studies looking at the association between clinical variables and QoL have reported a significant association between the number of daily medication, the presence of anxiety/depression symptoms, suicidality, comorbid medical problems and general psychopathology-9,34,35,36 and medication adherence. ${ }^{9,37}$ According to Akinsulore et $\mathrm{al}$, the presence of depressive symptoms, negative and positive symptoms of schizophrenia and frequency of relapse also predicts greater disability in patients with schizophrenia. ${ }^{36}$

Research studies have shown a significant association between medication dosage and medication adherence ${ }^{38,39}$ and medication adherence and QoL. ${ }^{9}$ This may further explain the association between number of antipsychotic medications and antipsychotic preparation with QoL noticed in this study. In this study, those who had oral or depot preparation alone were more likely to report better QoL than those who take a combination of the two. However, this may not be a function of numbers of medication but rather the severity of the illness, which may also correlate with the QoL.

One of the key parameters for measuring mental health care service outcome is patients' satisfaction..$^{40,41}$ In this study, the perception of patients' satisfaction with the outpatient clinic as assessed by the Charleston psychiatric out-patient satisfaction scale (CPOSS) was found to correlate well with the mean of the total WHO BREF scores of the two groups. This means that those who had a better perception of care were more likely to have a better QoL and vice-versa. Several studies have reported that those who have a better perception of care are more likely to experience a better QoL. ${ }^{42-45}$

There are some limitations to be taken into consideration in the interpretation of the findings. Of note is the use of a generic QoL questionnaire such as WHOQOL-BREF in this study which may exclude other features of QoL affected in persons with schizophrenia. 
However, most other studies looking at QoL in this population of patients have used similar instrument making comparison easier. Again, the result of this study was limited to just one community outpost and one major psychiatric hospital, which may not reflect the QoL of patients with schizophrenia in other similar centres in $\mathrm{Ni}$ geria. However, the strength of the study is that it is one of the few studies in Africa and to our knowledge the first from Nigeria providing information on the comparison of outcomes or QoL of patients treated at the community centre and typical psychiatric Hospital.

\section{CONCLUSION}

Although the two settings differ on one of the items on the WHOQOL-BREF variables, their overall quality of life was substantially similar, and their scores on various domains do not differ significantly, thus affirming that patients can be managed well in the community settings.

\section{ACKNOWLEDGEMENT}

The Authors acknowledge the support of Ogun State Community Psychiatric Service during data collection.

\section{REFERENCES}

1. Awad AG, Voruganti LNP, Heslegrave RJ. A conceptual model of quality of life in schizophrenia: description and preliminary clinical validation. Qual Life Res. 1997; 6:21-26.

2. Post WM. Definitions of Quality of Life: What Has Happened and How to Move On Marcel. Top Spinal Cord. Int J. Rehabil. 2014; 20(3):167-180.

3. Boggatz T. Quality of life in old age - a concept analysis. Int J Older People Nurs. 2015;11:55-69

4. Pintoa S, Laís FC, Mazzocco A, Caldeira S, Martins JC. Comfort, well-being, and quality of life: Discussion of the differences and similarities among the concepts. Porto Biomed. J. 2017; 2 (1):6-12.

5. Eack SM, Newhill CE. Psychiatric symptoms and quality of life in schizophrenia: a meta-analysis. Schizophr Bull. 2007; 33(5):1225-37.

6. World Health Organization, World Health Organization. WHOQOL: measuring quality of life. Geneva: World Health Organization: Division of Mental Health and Prevention of Substance Abuse; 1997.

7. Adewuya AO, Makanjuola RO. Subjective quality of life of Nigerian schizophrenia patients: socio-demographic and clinical correlates. Acta Psychiatr Scand. 2009; 120 (2):160-4.

8. Makara-Studzińska M, Wołyniak M, Partyka I. The quality of life in patients with schizophrenia in community mental health service - selected factors. JPCCR. 2011; 5(1):31-34.

9. Adelufosi AO, Ogunwale A, Abayomi O, and Mosanya JT. Socio-demographic and clinical correlates of subjective quality of life among Nigerian out- patients with schizophrenia. Psychiatry Research. 2012; 209(3): 320-325, 2013.

10. Bow-Thomas CC, Velligan DI, Miller AL, Olsen J. Predicting quality of life from symptomatology in schizophrenia at exacerbation and stabilisation. Psychiatry Res. 1999; 86(2):131-142.

11. Suttajit S, Pilakanta S. Predictors of quality of life among individuals with schizophrenia Neuropsychiatric Disease and Treatment. 2015; 11: 1371-1379.

12. Novick D, Montgomery W, Cheng Y, Moneta V, Haro JM. Impact of Negative Symptoms on Quality of Life in Patients with Schizophrenia. The value in health. 2015; 18: A805-A881.

13. Browne S Clarke M, Gervin M, Waddington JL, Larkin C, O'Callaghan E. Determinants of quality of life at first presentation with schizophrenia. Br J Psychiatry. 2000, 176; 173-176.

14. Fitzgerald PB, Williams CL, Corteling N, Filia SL, Brewer K, Adams A et al. Subject and observerrated quality of life in schizophrenia. Acta Psychiatr Scand. 2001; 103 (5):387-392.

15. Tomotake M. Quality of life and its predictors in people with schizophrenia. $J$ Med Invest. 2011; 58(3-4):167-174.

16. Priebe S, Roeder-Wanner U, Kaiser W. Quality of life in first-admitted schizophrenia patients: a follow-up study. Psychol Med. 2000; 30: 225-230.

17. Dan A, Kumar A, Avasthi S \& Grover S. A comparative study on quality of life of patients of schizophrenia with and without depression. Psychiatry Research. 2011; 189(2):185-9.

18. Araoye M. Research methodology with statistics for health and social sciences. Ilorin, Nigeria: Nathadex Publishers; 2003. p. 115-29.

19. Gholami A, Jahromi LM, Zarei E \& Dehghan A. Application of WHOQOL-BREF in Measuring Quality of Life in Health-Care Staff. Int J Prev Med. 2013; 4(7): 809-817.

20. Skevington SM, Lotfy M \& O'Connell A. The World Health Organization's WHOQOL-BREF quality of life assessment: Psychometric properties and results of the international field trial A Report from the WHOQOL Group. Quality of Life Research. 2004; 13: 299-310.

21. Akinpelu AO, Maruf FA, Adegoke BO. Validation of a Yoruba translation of the World Health Organization's Quality of Life Scale-Short Form among stroke survivors in Southwest Nigeria. African Journal of Medical Science. 2006; 4: 417-424.

22. Mas-Expósito L, Amador-Campos JA, Gómez-Benito J, Lalucat-Jo L. Research Group on Severe Mental Disorder. The World Health Organization Quality of Life Scale Brief Version: a validation study in patients with schizophrenia. Qual Life Res. 2011; 20(7):1079-89. 
23. Pellegrin KL, Stuart GW, Maree B, Frueh BC, Ballenger JC. A brief scale for assessing patients' satisfaction with care in out-patient psychiatric services. Psychiatric Services. 2001; 52:816-81.

24. Ukpong DI, Mosaku SK, Mume CO, Aloba O, Mapayi B. Reliability and validity of a satisfaction scale in a Nigerian psychiatric out-patient clinic. Niger $J$ Psychiatr. 2008; 6:31-5.

25. Dahlan R, Midin M, Sidi H \& Maniam T. Hospitalbased community psychiatric service for patients with schizophrenia in Kuala Lumpur: A 1-year follow-up study of re-hospitalisation. Asia-Pacific Psychiatr. 2013; 5: 127-133.

26. Nordentoft M, Knudsen HC, Jessen-Petersen B, KrasnikA et al. CCPP-Copenhagen Community Psychiatric Project. Implementation of community mental health centres in Copenhagen: effects of service utilisation, social integration, quality of life and positive and negative symptoms. Soc Psychiatry and Psychiatric Epidemiology. 1996; 31, 336-344.

27. Hahn SR, Kroenke K, Spitzer RL, Brody D, Williams JBW, Linzer M, et al. The difficult patient: prevalence, psychopathology, and functional impairment. J Gen Inter Med. 1996; 11:1-8.

28. Koekkoek B, van Meijel B, Tiemens B, Schene A, Hutschemaekers G. What makes community psychiatric nurses label non-psychotic chronic patients as 'difficult'? Soc Psychiatry Psychiatric Epidemiol. 2010; 46:1045-53.

29. Hsiung P, Pan A, Liu S, Chen S, Peng S, Chung L. Mastery and Stigma in Predicting the Subjective Quality of Life of Patients with Schizophrenia in Taiwan. Journal of Nervous and Mental Disease. 2010; 198: 494-500.

30. Lam JA, Rosenheck RA. Correlates of improvement in the quality of life among persons who are homeless and have serious mental illness. Psychiatr Serv. 2000; 51(1):116-118.

31. Hannson L, Middleboe T, Sorgaar KW, BengtssonTops A, Bjarnason O, Merinder L et al. Living situation, subjective quality of life and social network among individuals with schizophrenia living in community settings. Acta Psychiatri Scand. 2002; 106(5):343-350.

32. Xiang YT, Weng YZ, Leung CM, Tang WK, Ungvari GS. Quality of life of Chinese schizophrenia out-patients in Hong Kong: relationship to socio-demographic factors and symptomatology. Aust $N \mathrm{ZJ}$ Psychiatry. 2007; 41(5): 442-9.

33. Caron J, Lecomte Y, Stip E, Renaud S. Predictors of quality of life in schizophrenia. Commun Ment Health J. 2005; 41(4): 399-417.
34. Xiang YT, Weng YZ, Leung ChM, Tang WK, Ungvari GS. Subjective quality of life in out-patients with schizophrenia in Hong Kong and Beijing: relationship to socio-demographic and clinical factors. Qual Life Res. 2008; 17:27-36.

35. Benaiges I, Prat G and Adan A. Health-related quality of life in patients with dual diagnosis: clinical correlates. Health and Quality of Life Outcomes. 2012; 10:106. https://doi.org/10.1186/1477-752510-106.

36. Akinsulore A, Mapayi BM, Aloba OO, Olaniyi I, Fatoye FO, Makanjuola RO. Disability assessment as an outcome measure: a comparative study of Nigerian out-patients with schizophrenia and healthy control. Ann Gen Psychiatry. 2015; 23(14):40.

37. Ogunnubi OP, Olagunju AT, Aina OF \& Okubadejo NU. Medication Adherence among Nigerians with Schizophrenia: Correlation between Clinico-Demographic Factors and Quality of Life. Mental illness. 2017; 9:6889 10-15.

38. Saini SD, Schoenfeld P, Kaulback K \& Dubinsky MC. Effect of Medication Dosing Frequency on Adherence in Chronic Diseases. Am J Manag Care. 2012; 18 (3):139-146.

39. Srivastava K, Arora A, Kataria A, Cappelleri JC, Sadosky A, and Peterson AM. Impact of reducing dosing frequency on adherence to oral therapies: a literature review and meta-analysis. Patient Prefer Adherence. 2013; 7: 419-434.

40. Bramesfeld AWF, Elgeti H, Bisson S. How does mental health care perform with respect to service user's expectations? Evaluating inpatient and out-patient care in Germany with the WHO responsiveness concept. BMC Health Serv Res. 2007; 7(99):1-12.

41. Leonard KL. Is patient satisfaction sensitive to changes in the quality of care? An exploitation of the Hawthorne effect. J Health Econ 2008; 27(2):444459.

42. Blenkiron PC Hammill A. What determines patients' satisfaction with their mental health care and quality of life? Postgrad Med J. 2003; 79:337-340.

43. Boyer L, Baumstarck K, Boucekine M, Blanc J, Lançon C, Auquier P. Measuring quality of life in patients with schizophrenia: an overview. Expert Rev Pharmacoecon Outcomes Res. 2013; 13(3): 343-9.

44. Afe T.O., Bello-Mojeed M, \& Ogunsemi O. Perception of service satisfaction and quality of life of patients living with schizophrenia in Lagos, Nigeria. J Neurosci Rural Pract. 2016; 7(2): 216-222.

45. Cramm JM, Strating MMH, and Nieboer AP. Satisfaction with care as a quality-of-life predictor for stroke patients and their caregivers. Qual Life Res. 2012;21:1719-1725

Copyright (C) The Author(s). This is an Open Access article under the CC BY license. 